\title{
Disability Pension Rates Among Immigrants in Norway
}

\author{
Bjørgulf Claussen · Lisbeth Smeby • \\ Dag Bruusgaard
}

Published online: 28 December 2010

(C) The Author(s) 2010. This article is published with open access at Springerlink.com

\begin{abstract}
Immigrants from low-income countries are more likely than ethnic Norwegians to receive disability pensions. In a previous study in Oslo, we showed that occupational position probably accounted for all of this difference. The present article presents a study of the total population, with data on education and age at receipt of pension. Census and social security data for all persons living in Norway from 1992 to 2003 were used to identify new disability pensions to those aged $30-55$ years and eligible in 1992, comprising $15.9 \%$ females and $11.4 \%$ males. Age-adjusted relative risk was $2.03(95 \%$ CI 1.97-2.08) for non-Western males and 1.30 (1.26-1.36) for non-Western females compared with Westerners, and more than three times higher for males from North Africa/the Middle East. Education did not explain any of the risk differences, but when adjusting for age at pension receipt the differences disappeared completely. This is probably due to their being in predominantly unskilled occupations where there is also a low pension age among ethnic Norwegians.
\end{abstract}

Keywords Disability pension · Ethnicity - Immigrants · Minorities study $\cdot$ Register-based study

\section{Introduction}

Disability pensions are relatively generous in Norway, providing about $60 \%$ of former wages. In Norway, the working age is $18-66$ years, and $11 \%$ of this group

B. Claussen $(\varangle) \cdot$ L. Smeby $\cdot$ D. Bruusgaard

Department of General Practice and Community Medicine, University of Oslo, P.O. Box 1130, Blindern, 0318 Oslo, Norway

e-mail: bjorgulf.claussen@medisin.uio.no receives a disability pension [1]. This rate is high, and it occurs because the disability pension is almost the only way of compensated exit from work before the retirement age of 67 years. The eligibility criteria are being in work for at least 3 years and having lost at least 50\% of working ability because of disease, injury or inborn handicap. The disability pension is preceded by 1 year of sick leave with pay at $100 \%$ of wages, and is usually accompanied by rehabilitation, paid at the same rate as the disability pension. The tax-financed Norwegian Labor and Welfare Administration (NAV) is responsible for paying benefits and covers all persons living and working in Norway, independent of citizenship.

Immigrants from low-income countries are more likely to receive disability pensions than ethnic Norwegians, and this has been a contentious issue in public debate for many years. Immigrants are criticized for exploiting the social security system and for their poor work ethic. This is supported to some extent by the first studies of the issue in Norway, although the authors stated that low occupational level might explain the ethnic differences [2,3].

In Sweden between 1981 and 1999, foreign-born persons had higher rates of disability pension than persons born in Sweden [4]. The difference was not explained by education or marital status. Of 22 countries of origin, the highest rates occurred among immigrants from Greece, Yugoslavia, Turkey and Finland.

A Danish study of sickness absence among 3,121 healthcare assistants showed that although immigrants from developing countries reported worse health status than their Danish counterparts, they had significantly less sickness absence [5].

The authors conducted a study of disability pensions over the 5 years following a 2000-2001 health survey in Oslo $(n=11,072)$ [6]. An age- and gender-adjusted odds 
ratio of 2.27 (95\% CI 1.55-3.23) among immigrants from low-income countries compared with ethnic Norwegians declined to $0.88(0.46-1.67)$ when adjusting for occupation, working conditions and income. Adding self-reported health and mental distress reduced the odds ratio further, to the point where it was not significantly different from that of Norwegians, i.e. $0.63(0.32-1.25)$. Thus, adjusting for occupational differences is crucial. In a study of ethnic Norwegians, we found a very strong relation between disability pension and level of education, which may be a proxy for occupational position [7].

We wanted to test the hypotheses that the increased incidence of disability pensions among non-Western immigrants in Norway may be explained by differences in education level, and that they receive disability pensions at a lower age than ethnic Norwegians.

\section{Methods}

The data file "FD-trygd" links Statistics Norway's demographic and education data with files from NAV about disability pensions for the period 1 January 1992-31 December 2003 for all persons living in Norway [8, 9].

We chose a sample aged 30-55 years in 1992 because they were eligible for the disability pension over the whole period, with the oldest persons reaching retirement age after the study period and the youngest being old enough to get disability pensions for reasons other than inborn conditions. Those receiving the disability pension at 1 January 1992 were excluded, as were those not living in Norway on 31 December 2003.

\section{Disability Pension}

The dependent variable was cumulative incidence of disability pensions from 1 January 1992 to 31 December 2003, taken from the FD-trygd file without missing cases. In Norway, all disability pensions are assessed, wholly or partly, by the national social security system, NAV.

\section{Place of Origin}

We used the official definition of immigrants based on the country where the parents were born, namely in Norway, other Western countries, East European countries or developing countries [6]. Persons with one Norwegian parent were defined as ethnic Norwegians; otherwise, the more affluent of the parents' respective countries of birth was used. We dichotomized the population into Westerners and non-Westerners, the first group being ethnic Norwegians and immigrants from Western Europe, North America, Japan, Australia and New Zealand. In our population,
$92 \%$ of non-Western immigrants were born in their country of origin, i.e. they were first generation immigrants.

\section{Education}

We used education as a proxy for occupational level to assess risk of receiving a disability pension. Statistics Norway records all Norwegian education outcomes, while immigrants have their self-reported education registered by immigration authorities. This is not always done, and in our study the education levels of $7.1 \%$ of non-Western males, $7.3 \%$ of non-Western females, $2.7 \%$ of Western immigrants and $0.3 \%$ of ethnic Norwegians were not recorded. Because a large proportion of non-Western immigrants are in unskilled jobs [10], we imputed basic education, which corresponds with unskilled work, to the missing cases.

\section{Statistics}

Bivariate associations were tested by chi-square statistics and $t$ tests (Tables 1, 2, 4). Poisson regressions were used for computing relative risks of receiving a disability pension adjusted for age, education and age at pension receipt (Table 3).

\section{Results}

There were 1,330,832 inhabitants aged 30-55 years in 1992 who met eligibility criteria for a disability pension between 1992 and 2003. Of these, $15.9 \%$ of females and $11.4 \%$ of males received the pension in the period (Table 1). The incidence of pension receipt was $6.7 \%$ for those aged 30-39 years in 1992, $15.0 \%$ for those aged 40-49 years, and $30.0 \%$ for those aged 50-55 years.

Age-adjusted relative risk of getting a disability pension was more than three times higher for Middle Eastern/North African males that for ethnic Norwegians (Table 1). Asian males had the second highest relative risk, followed by East Europeans and other immigrants from developing countries, while Western immigrants had the same risk level as ethnic Norwegians. The differences were less marked among females, being twice as high for Middle Eastern/North African immigrants, followed by East European and Asian immigrants.

Non-Western immigrants were more likely to have basic education only (partly a result of imputing basic education for the $7.2 \%$ of cases with missing values) but they were also more likely to have had university or other long education (Table 2). Mean length of education for nonWestern immigrants with valid data was 11.5 years, and this was reduced to 11.3 years following imputation for missing data. These values are not very different from the 
Table 1 Frequency (vertical percent) of place of origin, incidence (horizontal percent) of a new disability pension in 1992-2003 and age-adjusted relative risk (RR) of inhabitants in Norway aged 30-55 years and not having a disability pension on 1 January 1992

\begin{tabular}{|c|c|c|c|c|c|c|}
\hline & \multicolumn{3}{|c|}{ Women $(n=648,406)$} & \multicolumn{3}{|c|}{$\operatorname{Men}(n=682,426)$} \\
\hline & Frequency & Incidence & RR & Frequency & Incidence & $\mathrm{RR}$ \\
\hline Norway & 92.5 & 16.1 & 1.00 & 92.1 & 11.3 & 1.00 \\
\hline Other Nordic & 2.5 & 13.6 & 0.92 & 2.3 & 9.6 & 0.98 \\
\hline Western Europe & 1.4 & 12.9 & 0.82 & 1.6 & 9.3 & 0.86 \\
\hline Eastern Europe & 0.6 & 16.8 & 1.27 & 0.5 & 14.9 & 1.48 \\
\hline Middle East \& North Africa & 0.3 & 23.9 & 2.06 & 0.7 & 25.1 & 3.39 \\
\hline Africa south of Sahara & 0.2 & 12.2 & 1.06 & 0.3 & 9.0 & 1.20 \\
\hline Asia & 1.3 & 14.8 & 1.19 & 1.2 & 18.0 & 2.06 \\
\hline North America & 0.9 & 11.0 & 0.82 & 0.9 & 8.6 & 0.89 \\
\hline Central \& South America & 0.3 & 14.3 & 1.15 & 0.3 & 10.0 & 1.15 \\
\hline Oceania & 0.0 & 13.7 & 0.96 & 0.0 & 8.2 & 0.91 \\
\hline Westerners & 97.2 & 15.9 & 1.00 & 97.0 & 11.3 & 1.00 \\
\hline Non-Westerners & 2.8 & 14.6 & 1.30 & 3.0 & 14.9 & 2.03 \\
\hline All & 100.0 & 15.9 & & 100.0 & 11.4 & \\
\hline
\end{tabular}

All differences are statistically significant $P<0.000$

Table 2 Educational level in 1992 by gender, frequency by ethnicity and incidence of new disability pension in 1992-2003 (percent)

\begin{tabular}{|c|c|c|c|c|c|c|c|c|}
\hline & \multicolumn{4}{|l|}{ Women } & \multicolumn{4}{|l|}{ Men } \\
\hline & \multicolumn{2}{|c|}{$\begin{array}{l}\text { Western } \\
(n=631,585)\end{array}$} & \multicolumn{2}{|c|}{$\begin{array}{l}\text { Non-Western } \\
(n=16,821)\end{array}$} & \multicolumn{2}{|c|}{$\begin{array}{l}\text { Western } \\
(n=661,759)\end{array}$} & \multicolumn{2}{|c|}{$\begin{array}{l}\text { Non-Western } \\
(n=20,667)\end{array}$} \\
\hline & Frequency & Incidence & Frequency & Incidence & Frequency & Incidence & Frequency & Incidence \\
\hline Basic & 17.6 & 27.9 & 31.0 & 17.1 & 16.6 & 22.4 & 23.4 & 18.9 \\
\hline Lower secondary & 39.9 & 18.0 & 20.1 & 15.7 & 28.4 & 14.9 & 24.1 & 16.9 \\
\hline Higher secondary & 13.9 & 9.2 & 17.3 & 13.8 & 24.3 & 8.6 & 19.5 & 14.1 \\
\hline College & 25.2 & 8.5 & 23.7 & 10.3 & 21.7 & 5.9 & 22.8 & 12.4 \\
\hline University & 3.1 & 4.7 & 6.8 & 7.0 & 8.1 & 2.9 & 8.4 & 5.5 \\
\hline Doctoral & 0.3 & 1.8 & 1.1 & 3.3 & 0.9 & 1.4 & 1.8 & 5.7 \\
\hline All & 100.0 & 15.6 & 100.0 & 14.0 & 100.0 & 11.4 & 100.0 & 14.9 \\
\hline
\end{tabular}

All differences are statistically significant $P<0.000$

Non-Westerners with missing education data were imputed as basic

mean of 11.7 years for Westerners. When adjusting for level of education (Table 3, model 1) the relative risks of pension receipt across ethnic groups were almost unchanged compared with Table 1. This somewhat surprising result could be explained partly by the relatively small differences in disability pension incidence across education levels in non-Westerners compared with the very large differences in pension incidence across education levels in Westerners (Table 2).

The relatively small differences in crude incidence could be explained by the lower mean age of non-Western immigrants compared with the total population, and their younger age when granted disability pensions. Age at pension receipt was highest for ethnic Norwegians and lowest for immigrants from the Middle East and North
Africa (Table 4), with a mean age of 52.6 years for Westerners and 48.9 years for non-Westerners $(P<0.000)$. All age-adjusted differences in relative risks for disability pension receipt were explained by immigrants from lowincome countries getting their pensions at lower ages than Western persons (Table 3, model 2).

\section{Discussion}

Among inhabitants of Norway aged 30-55 years, we find that immigrants from low-income countries, especially males, have higher age-adjusted relative risks of disability pension receipt than others, with male immigrants from North Africa and the Middle East having the highest 
Table 3 Age-adjusted relative risks for disability pension in 1992-2003 (95\% confidence interval) in two models across region of origin

\begin{tabular}{|c|c|c|c|c|}
\hline & \multicolumn{2}{|l|}{ Women } & \multicolumn{2}{|l|}{ Men } \\
\hline & Model 1 & Model 2 & Model 1 & Model 2 \\
\hline Norway & 1.00 & 1.00 & 1.00 & 1.00 \\
\hline Other Nordic countries & $1.03(0.98-1.07)$ & $0.99(0.95-1.04)$ & $1.01(0.96-1.06)$ & $0.99(0.93-1.05)$ \\
\hline Western Europe & $1.02(0.97-1.08)$ & $0.98(0.93-1.05)$ & $1.00(0.94-1.06)$ & $0.99(0.92-1.04)$ \\
\hline Eastern Europe & $1.47(1.36-1.59)^{*}$ & $1.00(0.91-1.07)$ & $1.63(1.50-1.77)^{*}$ & $1.00(0.94-1.06)$ \\
\hline Middle East \& North Africa & $1.84(1.68-2.01)^{*}$ & $1.01(0.93-1.11)$ & $3.08(2.90-3.27)^{*}$ & $0.97(0.92-1.04)$ \\
\hline Africa south of Sahara & $1.15(0.98-1.35)$ & $1.00(0.85-1.17)$ & $1.35(1.18-1.55)^{*}$ & $0.99(0.93-1.06)$ \\
\hline Asia & $1.10(1.04-1.17)^{*}$ & $1.02(0.96-1.08)$ & $1.92(1.83-2.02)^{*}$ & $1.01(0.91-1.10)$ \\
\hline North America & $0.97(0.90-1.05)$ & $0.99(0.92-1.07)$ & $1.05(0.96-1.14)$ & $0.99(0.91-1.08)$ \\
\hline Central \& South America & $1.27(1.12-1.43)^{*}$ & $0.96(0.91-1.02)$ & $1.19(1.03-1.37)^{*}$ & $0.97(0.85-1.12)$ \\
\hline Oceania & $1.16(0.83-1.63)$ & $1.05(0.75-1.46)$ & $1.15(0.74-1.78)$ & $1.09(0.70-1.69)$ \\
\hline Westerners & 1.00 & 1.00 & 1.00 & 1.00 \\
\hline Non-Westerners & $1.30(1.25-1.35)^{*}$ & $1.01(0.96-1.04)$ & $2.01(1.95-2.09)^{*}$ & $1.00(0.97-1.05)$ \\
\hline
\end{tabular}

Model 1 adjusted for age and education

Model 2 adjusted for age, education and age at pension receipt

* Statistically significant

Table 4 Mean age of a new disability pensioner in 1992-2003 by place of origin (years)

\begin{tabular}{lll}
\hline & $\begin{array}{l}\text { Women } \\
(n=103,234)\end{array}$ & $\begin{array}{l}\text { Men } \\
(n=77,805)\end{array}$ \\
\hline Norway & 52.2 & 53.3 \\
Other Nordic countries & 51.3 & 52.3 \\
Western Europe & 51.4 & 53.1 \\
Eastern Europe & 48.9 & 51.4 \\
Middle East \& North Africa & 45.8 & 47.3 \\
Africa south of Sahara & 48.6 & 48.9 \\
Asia & 48.7 & 50.0 \\
North America & 50.4 & 51.4 \\
Central \& South America & 49.7 & 52.3 \\
Oceania & 49.7 & 48.3 \\
Westerners & 52.3 & 53.3 \\
Non-Westerners & 48.4 & 49.4
\end{tabular}

All differences are statistically significant $P<0.000$

relative risk. Adjusting for education does not alter these risks, while the ethnic differences are fully explained by age at pension receipt.

\section{Strengths and Limitations}

The strengths of the present study are that it comprises all inhabitants in Norway and all those granted disability pensions, and that the data have good reliability. The large population size allows us to divide immigrants into small groups and still get statistically significant results (Tables 1 ,
2, 4). It also means that relatively small differences are statistically significant, for example the difference between $14.9 \%$ of Western males and $16.9 \%$ of non-Western males with secondary school education. Thus, we will only comment on differences that we regard as having considerable significance.

An important limitation in our study is lack of data on occupation, which is highly relevant to early exit from work [6]. In a study of disability pensions granted to Norwegians from 1996 to 2003, we used income in 1992, 3 years before pension receipt, as a proxy for occupational level [6]. It was not possible to do this in the present study, because commencing it in 1996 would have resulted in a population with too few immigrants.

Results

In a previous study, we found that the incidence of disability pensions decreases markedly as level of education rises [7]. Therefore, it is surprising that education does not explain any of the ethnic differences in disability pensions. More non-Westerners than Westerners in Norway have education levels beyond lower secondary school (Table 2) and, accordingly, should have lower disability pension rates than ethnic Norwegians. The explanation must be that there is a weaker association between occupation and education level for immigrants from low-income countries than for Westerners.

We know from a health study in Oslo with data on occupation that immigrants from developing countries often work in unskilled jobs with high pension rates or in jobs that do not match their level of education [6], and the 
same ethnic differences in occupation are probably true for our present population from the whole of Norway [10].

All the ethnic differences were explained by age at pension receipt, that is, non-Western immigrants receive the disability pension at a younger age on average than ethnic Norwegians. If our previous results from Oslo are valid for the whole country, immigrants are often working in unskilled jobs. The present results indicate that immigrants get their pension according to the normal practice in their respective occupations. If this is true, then it should not be necessary to implement special efforts to reduce the level of disability pensions among non-Western immigrants [11]. Instead, attempts should be made to reduce or postpone the receipt of disability pensions in unskilled and low-status occupations for all ethnic groups.

Acknowledgments We thank Agata Wrzos-Kaminska for linking data in Statistics Norway. The study is financed by our appointments at the University of Oslo.

Open Access This article is distributed under the terms of the Creative Commons Attribution Noncommercial License which permits any noncommercial use, distribution, and reproduction in any medium, provided the original author(s) and source are credited.

\section{References}

1. Rikstrygdeverket. Social Security Yearbook 2005 (in Norwegian). Oslo: Rikstrygdeverket, 2005.
2. Grünfeld B, Noreik K. Disability pensions among immigrants in Oslo (in Norwegian). Tidsskr Nor Laegeforen. 1991;111:1147-50.

3. Grünfeld B, Noreik K. Use of health insurance and social benefits among immigrants in Oslo (in Norwegian). Tidsskr Nor Laegeforen. 1992;112:365-7.

4. Osterberg T, Gustafsson B. Disability pension among immigrants in Sweden. Soc Sci Med. 2006;63:805-16.

5. Carneiro I, Ortega A, Borg V, Høgh A. Health and sickness absence in Denmark: a study of elderly-care immigrant workers. J Immigr Minor Health. 2010;12:43-52.

6. Claussen B, Dalgard OS, Bruusgaard D. Disability pensioning: can ethnic divides be explained by occupation, income, mental distress, or health? Scand J Public Health. 2009;37:395-400.

7. Bruusgaard D, Smeby L, Claussen B. Education and disability pension: a stronger association than previously found. Scand J Public Health. 2010 Aug 13. [Epub ahead of print].

8. Rege M, Telle K, Votruba M. The effect of plant downsizing on disability pension utilization. J Eur Econ Assoc. 2009;7:754-85.

9. Claussen B, Dalgard OS. Disability pensioning: the gender divide may be explained by occupation, income, mental distress and health in the Oslo Health Study. Scand J Public Health. 2009; 37:590-7.

10. Villund O. Right job according to education? A register based study of competence and work tasks for employed with immigrant background (in Norwegian). Report 2008/37. Oslo: Statistics Norway; 2008.

11. Quill BE, Aday LA, Hacker CS, Reagan JK. Policy incongruence and public health professionals' dissonance: the case of immigrant and welfare policy. J Immigr Health. 1999;1:9-18. 